\title{
PRECONCEITO LINGUÍSTICO: INTOLERÂNCIA QUE RETRAI, LÍNGUA QUE MARGINALIZA
}

\section{ARTIGO ORIGINAL}

SANTOS, Patrícia da Cruz Ferreira dos ${ }^{1}$

ANDRADE, Marta Mires Da Cruz de ${ }^{2}$

ALMEIDA, Daiane Vithoft de ${ }^{3}$

SANTOS, Patrícia da Cruz Ferreira dos. ANDRADE, Marta Mires Da Cruz de. ALMEIDA, Daiane Vithoft de. Preconceito linguístico: Intolerância que retrai, língua que marginaliza. Revista Científica Multidisciplinar Núcleo do Conhecimento. Ano 05, Ed. 08, Vol. 15, pp. 12-33. Agosto de 2020. ISSN: 2448-0959, Link de acesso: https://www.nucleodoconhecimento.com.br/educacao/lingua-que-

\section{marginaliza}

\section{RESUMO}

A Sociolinguística é uma disciplina da linguística a qual tem como finalidade o estudo da língua vernácula e sua transmutação, tendo-a como um princípio geral e universal, passível de ser descrita e analisada cientificamente. Este estudo objetivou combater o preconceito no âmbito sociolinguístico, bem como apontar soluções para defrontar a discriminação linguística; constatar as consequências causadas pelo preconceito; apresentar as diferentes motivações da mutação linguística; apontar os mitos sociolinguísticos. Para tanto, foi utilizado como método para recolhimento de informações a pesquisa bibliográfica, através do estudo levantado no referencial

${ }^{1}$ Graduação em Letras e suas Respectivas Literaturas. Graduação em Teologia Ministerial.

${ }^{2}$ Graduação em andamento em serviço social.

${ }^{3}$ Orientadora. 
teórico sobre a temática: Preconceito linguístico: Intolerância que retrai, língua que marginaliza. Embasado na sondagem de conceitos foi possível entender a relevância da nossa língua e os desafios nela existente. Devemos ter sempre em mente que todos os vocábulos cientificamente falando são iguais, não há melhor, nem mais fácil ou pior. Enfim, mediante a toda a análise consumada foi válido constatar que o preconceito linguístico é comum, assim como os outros e resulta de pareceres tendenciosos dos grupos protocolares e precisa-se ser combatido com perspicácia e intensidade.

Palavras-chave: Sociolinguística, língua materna, preconceito linguístico.

\section{INTRODUÇÃO}

Como bem nos assegura Leite (2012), pode se dizer que intolerância e preconceito são expressões com sentidos parecidos. Nesse contexto, fica claro que ambas as manifestações são atos de criticar, uma crença ou atitudes de seres que possuem essa abstração cuja um modo de pronunciar-se é melhor ou superior às outras formas. Por não ter domínio dos padrões e das regras do português brasileiro, o falante nativo é a vitima predominante desse procedimento. À vista disso, a sociolinguística atual busca procedimentos e estratagemas de adequação e um profundo estudo da língua vernácula e das mudanças linguísticas brasileiras para combater este manifesto. A sociolinguística entende a expressão tal como um advento ecumênico e absoluto, susceptível de ser tipificada e notada rigorosamente, com o objetivo de minimizar este fenômeno.

A linguagem instruída na esfera acadêmica é diferente da que usamos no cotidiano. Parece artificial distante da nossa realidade, mesmo para os emissores altamente escolarizados e moradores de centros urbanos.

Logo, colheram-se informações com destinação de redarguir a seguinte problematização: Quais fatores influem para a subsistência do julgamento linguístico? O que poderá ser feito para combater essa situação? 
A junção das palavras: variante, dialeto, intolerância, linguística e língua leva-nos a percepção total que transcorre a vigente pesquisa científica, a de chegar a um consenso entre as diferenças naturais dos seres e dos seus pré-julgamentos. À vista disso, o trabalho visa cooperar com o intuito de aniquilar o preconceito no âmbito sociolinguístico; apontar soluções para combater a implicância linguística; constatar as consequências causadas pelo preconceito; apresentar as diferentes motivações da variabilidade linguística; aguçar as lendas sociolinguísticas.

De forma geral, a língua nativa tem uma função de extrema significância para o progresso dos brasilienses, tanto na vivência profissional como na ótica social, desvendando-lhes o mérito e a imprescindibilidade de se depreender a acepção da transmutação diacrônica e os haveres de usos delas para o aprendizado da linguagem materna, bem como as incumbências do educandário, com esse acontecimento. Nesse cenário o tema pesquisado decorre devido às dificuldades de digladiar o prejulgamento da língua, em contribuição para o povo e os ganhos aos combatê-los.

Para o prosseguimento do vigente trabalho foram aplicadas pesquisas bibliográficas de natureza explicativa, realizada por intermédio da leitura sistemática e produção de fichamentos, baseados em livros, artigos e fontes eletrônicas que aludem a tese alegada para esgrimir esta situação difícil. Por seu turno, essa pesquisa identificou as razões pelas quais causam este prejuízo, aprofundou a gnose do fato, explicando o motivo da existência de julgamentos e de intolerâncias na nossa língua. A consulta bibliográfica explicativa busca elucidar os feitos de maneira precisa. Estuda um contexto de infortúnio e por meio do experimento tentativa e erro, identifica e esclarece o que colabora para o acontecimento do fenômeno.

O trabalho acadêmico está dividido em cinco tópicos, a introdução antecede e expõe um efêmero panorama ao conteúdo, o propósito e a meta realizada. No segundo é apontada a história e definições acerca da Sociolinguística. O terceiro menciona a crendice linguística, sua definição, onde e quando surgiu, foca acerca da língua espontânea, sendo expostos temas como variação linguística, norma padrão e não padrão da língua. No quarto, relata as práticas obtidas pelo homem como componente de uma sociedade. 
O quinto e o sexto tópico trata-se da metodologia e das considerações finais, fazendo - fechamento da argumentação enquadrando as principais conclusões e contribuições.

\section{VISÃO A CERCA DA SOCIOLINGUÍSTICA}

A sociolinguística especula a língua em seu enfoque social tendo-a como um fator homogêneo e não heterogêneo. Nesta conjuntura, fica preciso que essa disciplina estuda as relações no âmbito de linguagem e sociedade, para Aragão (2015, p. 794) "os seres humanos vivem organizados em sociedade sendo detentores de um combo de elementos de comunicação oral, uma língua". O mais preocupante, todavia, é averiguar que o proposito do aprendizado da língua vernácula e de variação brasileira, entendendo-a como um princípio geral e universal, passível de ser exposto e analisado cientificamente, com intuito de combater essa crendice.

Conforme verificado por Aragão (2015), a sociolinguística analisa o linguajar do ser humano como fator social. Trata-se inegavelmente de apontar os mitos sociológicos, seria um erro, porém, atribuir o dialeto que nem alicerce homogêneo e estável. Assim, atribui-se da importância de matutar acerca do estudo dessa disciplina e no nosso cotidiano. Sob essa ótima, ganha particular relevância que os aprofundamentos de base sociológica têm trazido resultados plausíveis para 0 entendimento da variabilidade da linguística, do saber e da coletividade.

É interessante, aliás, dizer que independentemente do fator linguístico ser um escopo de estudo de cada fala, nem sempre o aspecto social foi visto como relevante comparado ao século XX. Essa comparação será feita em dois momentos. No primeiro será usado na época do estruturalismo/gerativismo, correspondendo à homogeneidade; o segundo considerará a teoria da mudança como modo de projetar o futuro. Conforme explicado acima, todos os dados usados são de suma relevância para a reflexão acerca do vínculo junto à base linguística/social e os divergentes motivos da variante linguística. 
Conforme Bagno (1998), a diversidade tem que ser peça primordial do ensinamento. O autor é categórico em suas declarações quando diz que o falar não serve apenas para que possamos propagar ou obter informações; ela serve para estabelecer e manter relacionamentos com outras pessoas e comparece em todas as nossas atividades diárias, assim reveste-se de grande importância lembrar que linguagem cujos ingredientes fundamentais para a vida em sociedade e está relacionada à maneira como interagimos com as pessoas. Fica evidente que para compreender melhor o âmbito linguístico na qual vivemos, é preciso entender que nenhuma língua é melhor ou pior que outra; todo sistema linguístico é apto de expressar adequadamente a cultura de seu povo.

No seu exemplar do ano de 1999, o autor é bastante objetivo, pois alude o vocábulo como um fato ativo e as línguas alteram-se com o tempo. Nesse cenário, fica explícito as evidencias entre os autores, pois confirma todo o conteúdo estudado. O mais assustador é reconhecer que tanto a palavra quanto os sons e gestos que possibilitam a comunicação são matérias vivas. Não é demasia ratificar quão a sociolinguística equivale à área que examina a língua em seu emprego real, é relevante ter em consideração as relações entre as estruturas linguísticas, os aspectos sociais e culturais da produção linguística. "A língua varia tanto quanto a sociedade varia" (BAGNO,1999, p.16).

Assim, conforme mencionado pelo autor, aflige na verdade que para a língua continuar sendo a expressão do poder social demostrado por um idioma, as regras gramaticais deveriam mudar isso uma vez que, a sociolinguística tenciona correlacionar fatos linguísticos do âmbito gramatical da fonologia, da morfologia, da sintaxe, como: fatos sociais, classe, gênero, idade e identidade.

Entretanto a linguística, assim como diversos campos do conhecimento, é dividida em áreas que se especializaram em enfocar seu agente de investigação por um determinado ângulo. Só para recordar, o objeto estudado pela Linguística é os morfemas. É importante saber como o palavreado no que lhe concerne, é usada para diferir as pessoas, as camadas sociais a que elas pertencem, revestindo-as de poderes e de fraquezas, de estigmas e de preconceitos. De acordo com a explicação 
acima, os símbolos sonoros expande a comunicação oral através da exposição de ideias. Amplia os conhecimentos sobre o sistema de escrita, trocando experiências e discutindo a grafia das palavras. Realiza atividades em grupo, compartilhar decisões e respeita opiniões. A linguagem, a título de exemplo, é uma empreitada multidisciplinar (CORRÊA, 2006).

Em conformidade com Aragão (2015, p. 794):

A linguagem está presente em todas as atividades humanas, estabelecendo comunicação entre os homens. Ela é responsável para se aprender escrever e explicar a visão de mundo de um grupo sociolinguístico-cultural, e suas relações em contexto, surgindo, assim, o léxico como o nível da língua que melhor desempenha essa função.

O autor deixa claro na citação acima que o foco da sociologia da linguagem é mostrar que a mesma está presente no nosso cotidiano humano e social. Esse é o motivo pelo qual é importante frisar esse ponto, visto que, a omissão dessa disciplina pode comprometer a conexão entre a sociolinguística. Conforme citado acima o léxico e a conscientização dos discentes são formas de minimizar essa situação, fazendo assim com que não caiam nessas armadilhas preconceituosas e acabem prejudicando a ainda mais a o corpo social.

Esses dados revelam que não perfaz uma população de fala homogênea, nem um falante-ouvinte ideal. Pelo contrário, essa presença de alteração e de estruturas heterogêneas nas comunidades de fala é uma circunstância comprovada. Existe variação inerente à biocenose de dicção, não existem dois falantes que se expressam do mesmo modo, nem mesmo um falante que se expresse da mesma maneira em diferentes situações de comunicação. Fica notório, diante dessa busca teórica de sinais não é uma entidade que está dentro de um recipiente e deve ser retirada para instrumento de estudo. Ela está a qualquer momento, interagindo com o ambiente. Para lidar com esses códigos, é imprescindível olhar para os dados de fala da rotina e confrontá-los às teses gramaticais o mais justo possível, ajustando a teoria de forma que ela dê conta do objeto. 


\subsection{SOCIOLINGUÍSTICA NA ATUALIDADE}

A Sociolinguística surgiu no decenário de 1960 nos Estados Unidos, salvo de a linguística ser um saber cujo objeto é a descrição das línguas típicas, nem sempre o aspecto foi visto como relevante. Meillet (1866-1936), no começo do século XX, marca a fala como um sucedido social. John Gumperz (1996) assim se expressou: Na atualidade, e especialmente durante a última década, tornou-se uma matéria primordial preocupada com todos os aspectos da comunicação verbal nas sociedades humanas.

Como bem nos assegura John Gumperz (1996), pode-se admitir que nos dias que correm, a sociolinguística é uma área de ampla investigação com resultados impressionantes nas descrições das línguas. É essencial, contudo constatar-se quão - estudo dessa disciplina é relevante para elucubrações da linguagem. A Sociolinguística nasceu marcada por uma origem interdisciplinar que inclui a contribuição de disciplinas como a sociologia da linguagem, a linguística, a antropologia, a etnografia da comunicação, entre outras.

Diante de toda essa prossecução resume-se o quanto a Sociolinguística é hoje uma disciplina autônoma, pois apresenta particularidades características, tendo como agente de estudo a pluralidade linguística, a língua vulgar, observada, descrita e analisada em seu contexto social, em suas situações reais de uso. É válido, aliás, ratificar a constatação de que, ao estudar qualquer comunidade linguística, a conclusão imediata é a existência da diversidade ou da variação.

Conforme explicado acima é interessante, ainda dizer que todo e qualquer colóquio executado por qualquer comunidade, exibirá variações, mas há alguns fatores que se justapõe como, nenhuma língua se mostra como entidade homogênea e, ao estudála, a Sociolinguística irá deparar- se com variedades linguísticas existentes na mesma comunidade, cujo conjunto constitui o repertório verbal dessa biocenose, ainda que nunca seja arbitrário, pelo contrário, é motivado e organizado dentro de regras próprias, mesmo assim não podemos assegurar que a Sociolinguística não vê as variações como um problema a ser resolvido, ou como algo distante do preceito, 
todavia é preciso ser extinto, ao invés disso, visa à variação como uma qualidade em seu processo constitutivo. Conforme explicado acima se entende então que a expressão oral é mesclada de variedades.

A Sociolinguística considera em especial como motivador de estudo exatamente a variação, entendendo-a como um princípio geral e universal, passível de ser descrita e analisada cientificamente. Ela parte do pressuposto de que as alternâncias de usos são influenciadas por fatores estruturais e sociais. Tais fatores são também referidos como variáveis independentes, no sentido que os usos de estruturas linguísticas são motivados e as alternâncias configuram-se por isso sistemática e estatisticamente previsível. (MOLLICA, 2004, p.10).

A contribuição do confronto entre variedades do idioma brasileiro evidencia o quanto o dialeto não se enquadra no interior de uma norma singular, ou seja, a mesma varia ao longo dos dias, meses, ano e no ambiente. É importante ressaltar a inexistência nada inerente a uma variante que a defina como "bom", "ruim", "correto", ou "incorreto". A sociolinguística é uma ciência, não uma filosofia ou ideologia, todos os dialetos são "corretos". Cada um deles tem sua gramática, sua lógica, sua pertinência, sua adequação social. Não há um "padrão correto" óptica científico, contudo, há um "padrão de prestígio", porque esse "padrão" é o dos grupos dominantes.

\section{PRECONCEITO LINGUÍSTICO}

Pode imaginar o preconceito como ação de julgar como certas ou erradas ações e reações perante a sociedade, podendo ser conceituado como controle social e é evidente também na linguagem. "Preconceito é a ideia, opinião, ou o sentimento que pode conduzir o individuo a intolerância, à atitude de não dividir opinião divergente" (LEITE, 2012, p. 20).

O prejulgamento é, portanto, o julgamento negativo da falta de concórdia no discurso dos iletrados do Brasil. Afinal é por culpabilidade da didática linguística tão somente pautada na gramática normativa e da preponderância inconsciente da mídia em massa, a nação brasileira sofre com um intenso preconceito linguístico. (BAGNO, 2004), afirma que é imprescindível entender que nenhuma língua é melhor ou pior que outra; toda tese linguística é apta de pronunciar-se corretamente o saber de seu povo. 
Ora, em tese, muito se ouve falar na contemporaneidade sobre preconceitos, mas não se loque-la em preconceito linguístico. Conforme explicado acima à cisma é igual ou pior a hostilidade de classe social, sexo, religião, entre outros. Não se trata de um paradoxo, lamentavelmente, esse espécime de preconceito é tido como natural pela maior parte da sociedade. É importante reputar que ele existe. Julgo pertinente trazer à baila quão imprescindível é combater este modelo de preconceito tanto quanto qualquer outro tipo.

Conforme listados pelos PNS (BRASIL, 1988), é perceptível como a implantação de ensino precisa dispor-se de múltiplos mitos preconceituosos em torno da língua. É indiscutivelmente o quanto é relevante eliminar essas crenças linguísticas, que dissemina a ideia da desconfiança e apenas reforça o desígnio cuja linguagem é um mecanismo de poder simbólico. A linguagem é um mecanismo da comunicabilidade, e deve ser usada de forma igualitária, seria um equívoco, contudo, impor que só a língua dos padrões acadêmicos possui gramática. Assim, reveste-se de particular importância que a expressão é um constituinte ativo, variável e pertence àqueles que a utilizam no cotidiano nas inúmeras situações comunicacionais. Isso não quer dizer que o preceito erudito deve ser eliminado, mas sim que se deve ter sensatez de adaptar a manifestação às variadas situações de uso. Sob essa ótima, ganha particular relevância a implicância que serve apenas para humilhar falantes que possuíram pouco acesso aos estudos propagados nas escolas e instituições, deve ser indagado e vencido.

Pode-se dizer que preconceito linguístico é qualquer crença sem fundamento científico acerca das línguas e de seus usuários e é preciso ter-se uma postura de defesa diante de qualquer preconceito da língua. Conforme mencionado pelo autor, "esse comportamento de hostilidade deve ser combatido com vigor e energia". PCN [Parâmetros Curriculares Nacionais] (BRASIL,1998, p.82).

A melhor maneira de compreender esse processo é acreditar que a discriminação social através da linguagem pode ser combatida. Conforme explicado acima fica claro à mostra a ideologia de exclusão social e de dominação política pela língua, típica das sociedades ocidentais. Julgo pertinente trazer á tona, por exemplo, que o combate a estes atos passa principalmente pelas práticas escolares. 
Parece haver cada vez mais, nos dias de hoje, uma forte tendência a lutar contra as mais variadas formas de preconceito, a mostrar que ele não tem nenhum fundamento racional, nenhuma justificativa e que é apenas o resultado da ignorância, da intolerância ou da manipulação ideológica. Infelizmente, porem, esse combate tão necessário não tem atingido um tipo de preconceito muito comum na sociedade brasileira: o preconceito linguístico. (BAGNO,1999, p. 23).

O autor deixa patente na citação acima a existência de uma necessidade de combater os preconceitos, mas, no que compete à linguagem essa necessidade fica menos evidente. Esse é o motivo pelo qual é importante frisar esse ponto, uma vez que, esse preconceito existe e é sutil. Conforme dito acima a única forma conhecida de combater esse problema é identificá-lo e resolvê-lo.

Conforme explicado acima o que importa, portanto, é compreender que a opinião antecipada em relação à forma de se expressar é um problema histórico e só pode ser contido se, nos padrões de ensino, independentemente da área de conhecimento, levarmos em conta os princípios de agrupamento sociável que explicitam o valor imputado a determinados traços sociais e linguísticos, em dano de outros semelhantes. Essa, porém, é uma tarefa que exige prudência aos profissionais de educação. Vê-se, pois, que sua função é minimizar de alguma forma o crescimento desse preconceito.

\subsection{CONHECENDO O PRECONCEITO LINGUÍSTICO}

Á frente de uma profunda análise, dito preconceito linguístico nasceu no exercício do respectivo idioma, ou seja, como fruto do convívio entre os humanos. Historicamente, outrora, no momento em que se falava em preconceito não se dirigia ao sentido emblemático nocivo que sugere atualmente. Mariani (2008) nos assegura que intolerância expressa uma concepção que é formulada precedentemente em todos os princípios que pormenorizam situações antes mesmo de terem sido examinados.

O prejulgamento pode desestruturar uma pessoa socialmente trazendo-as consequências irreversíveis. 
Como bem nos assegura Mariane (2008), o ato de julgar antecipadamente consiste na discriminação existente entre pessoas falantes do mesmo idioma que elege esse outro idioma como oficial e exclui outras variações existentes. O mais relevante, no entanto é saber que este ato surge da relação humana. Em todo esse processo pode-se dizer de forma resumida que grande parte da pré-noção é gerada por a ausência de ponderação. É interessante, aliás, afirmar a subsistência de mais elementos que se sobrepõe como, os mitos linguísticos os quais são causados por falsas ideias que rodeiam a língua materna.

Conforme explicado acima o preconceito ocorre devido às variedades linguísticas, o fator social, propagandas irônicas referentes a sotaques da mídia e redes sociais, muitas padrões acadêmicos caracterizados pela discriminação, dentre outras causas. Isso traz graves consequências, pois prejudica o desempenho escolar, já que desestrutura uma pessoa socialmente como, por exemplo, as vitimas acaba se achando inferiores as outras pessoas, sem vontade de se expor por medo do que os outros vão falar dela.

Ainda se ver esse preconceito ser nutrido a cada dia em programações televisivas e de rádio, em colunas de jornal e revista, sem falar, é claro, nos métodos tradicionais de habilitar a língua. O feito fica bastante claro em certo tipo de afirmação que já fazem parte da negatividade que o brasileiro tem de si mesmo e da língua falada por aqui. (BAGNO, 2007, p. 13).

Enfim, podemos chegar à inferência que o ensinamento de língua oriunda é uma contestação extremamente relevante para a nossa nacionalidade. Logo, é indiscutível, pois, isso é decorrente não obstante ao fato de a língua portuguesa constar-se como constituinte da grade curricular, porém, acima de tudo, por ela ser um mecanismo de reconhecimento de uma pessoa. Nesse sentido, é viável alegar o quanto a instituição educandário junto aos professores devem considerar a realidade do corpo discente e desenvolver práticas e procedimentos que valorizem as vivências e a realidade dos alunos, cm o objetivo de que eles se sintam valorizados, tanto como indivíduos quanto como falantes da língua. 


\subsection{O PRECONCEITO LINGUÍSTICO EM RELAÇÃO À LÍNGUA VERNÁCULA E DIVERSIDADE LINGUÍSTICA}

O prejulgamento linguístico respalda-se na abstração cuja uma variante da língua portuguesa pode ser considerada da mesma, melhor dizendo, a variante adotada pela minoria dominante. Nesse caso, Bagno (2001) alega que seja qual for a diversidade da língua, esta não deve ser rejeitada ou menosprezada. Para combater ou minimizar esse círculo vicioso é preciso ter consciência dos objetivos da língua materna.

Qual a importância de ensinar português? Que objetivo pretende-se alcançar com a prática em classe? De fato, o que seria falar corretamente no nosso país? Essa matéria tem o propósito, em qualquer série, desvendar como funciona a linguagem humana em todas as suas possibilidades e proporcionar ao discente percepção para entendê-las tanto na oralidade quanto na escrita. Como bem nos endossa Bagno (2007), o ensinamento da norma culta, a monomania terminológica, a paranoia classificatória, o apego à nomenclatura, nada disso serve para formar um bom usuário da linguagem em sua modalidade culta.

O discente precisa tornar-se um falante frequente da língua, que fala e escreve não uma pessoa de decorar regras. Conforme explicado acima é preciso entender que dominar a língua culta não significa dominar regras. É claro que existe uma imposição de regra para que ocorra uma escrita sem erros, visto que a defesa da anarquia linguística, com certeza, não é a meta dos conceituados e intelectuais da língua, unicamente que seja rompida o obstáculo que mantém distintos os preconceituosos que discorrem e dominam (não absolutamente, visto que não ocorre se quer concórdia entre ambos) a língua protótipo e as outras variáveis.

Precisamos possibilitar aos nossos alunos que sejam usuários competentes da língua. Para atingirmos isso, não precisamos nem devemos fazer com que decorem diretrizes gramaticais como nós, professores, precisamos saber, não para cobrar deles, mas para saber ensinar a língua de fato. É interessante mostrar a eles, ou fazê-los lembrar de que as obrigações sociais exigem que nos adaptemos linguisticamente às situações, ou seja, situações sociais díspares 
exigem registros diferentes: é preciso que haja graus diversos de requisito e cortesia, por exemplo. (SILVA, 2013, p.188).

É preciso salientar que, outro modo interessante de romper com o círculo vicioso desse motor de estudo é reavaliar a noção de "erro". Esse julgamento é fruto de uma narrativa de prescrição do falar e escrever corretamente que leva os indivíduos a se acostumarem a supor que todo o formato desigual das normas gramaticais inclusas nos livros que estudam são "erradas". Fica óbvia diante dessa situação a inexistência do errado, mas o diferente; e regra, à vista disso, não significa "prescrição", mas uma sistematização linguística do falante conforme a variedade de sua comunidade linguística.

\subsection{LÍNGUA MATERNA E VARIAÇÃO LINGUÍSTICA}

A língua materna também se conhece como idioma materno, língua nativa ou primeira língua. A variante apura o modo de falar que nem um ponto histórico-cultural, a qual muda a todo o momento e a qualquer hora. O jargão é mesclado de variedades cujas mudanças são inerentes às línguas natas. Segundo Labov (1983) a variação existe em todas as línguas naturais humanas.

Como bem nos assegura Guimarães (2012) pode-se dizer o quanto o linguajar varia de um local para outro, de uma comunidade para outra, de uma condição para outra. Nessa contextura é correto afirmar que as multiplicidades são as representações viáveis do idioma. Além do mais, tem que certificar-se que não é apenas no modo oral que sucede a pluralidade linguística, não é exagero afirmar que esse fenômeno é real e ocorre tanto na fala quanto na escrita. Em todo esse processo expõe-se que a variação ocorre, em consequência da dimensão territorial da nação que não proporciona um convívio intenso no âmbito regional e da desigualdade social, desmerecendo a expressão aos menos privilegiados financeiramente. É interessante, aliás, afirmar que em uma nação como o Brasil, mesmo sendo ímpar, a linguagem nunca é empregada igualmente por todos, apresenta-se distinções morfossintáticas, fonológicas e semânticas nas diferentes áreas, mas há alguns fatores que impõe 
como, atentar que poucos atos de deformações linguísticas estão associados isocronamente à identidade do ouvidor e à do falante.

Conforme Goffman (2002) é quase fictício referir-se a uma variedade social que ao manifestar-se não origine consequências sobre o comportamento linguístico: idade, sexo, condição, raça, país de origem, geração, região, escolaridade; pressuposições cognitivo-culturais; bilinguismo, e assim sucessivamente. $O$ autor deixa claro o quanto o dito similar do individuo pode diversificar-se, em conformidade das situações sociáveis, em outras palavras, de acordo com o ambiente, o assunto, a posição social do interlocutor etc.

Na visão de Labov (2006) não existe uma comunidade de fala homogênea, nem um falante ouvinte ideal. Conforme mencionado pelo autor, o vestígio de alteração e de estruturas heterogêneas nas comunidades de fala é um sucedido comprovado. Nesse contexto, ficam claro que se pode afirmar a ausência do melhor pronunciamento, mais belo, todos é o Português atuando no incônscio dos emissores. "Todas as variedades linguísticas se equivalem, todas obedecem a regras gramaticais que podem ser descritas e explicadas" (BAGNO, 2007, p. 48).

A língua portuguesa é pronunciada entre quase 300 milhões de pessoas espalhada por oito países. Será que todas elas a usam da mesma maneira? É claro que não. Conforme o que foi esclarecido acima o modo de falar é mudável independente do lugar e do período. A divergência entre o português brasileiro e o proveniente da Europa está diretamente alusivo às diversos hábitos e experimentos de cada povo, as alterações demográficas, socioculturais, políticas econômicas, convertem o rumo dos dialetos. No aspecto do dialeto do Brasil, por exemplo, o contato linguístico institui um motivo de modo especial expressivo.

As línguas utilizadas para comunicação humana consistem em sistemas dinâmicos, heterogêneos; quer dizer, as línguas estão sujeitas à variação e à mudança. $O$ fenômeno da variação linguística revela que, nos diferentes níveis de uma língua (fonético-fonológico, morfossintático, ou semântico-pragmático) podem coexistir diferentes formas de igual valor, passíveis de ser substituídas umas pelas outras. (TASCA, 2002, p.17). 
Segundo o autor na citação acima a variante constitui uma veracidade efetiva na comunicação, competiria ao educandário responsabilizar-se com a variação onde o educando teria capacidade de acessar às inúmeras multiplicidades da forma de falar e, além disto, compreender em quais circunstâncias sociais é capaz de valer-se de qualquer variante, e em nenhum momento delimitar o ensinamento do dialeto a regra padronizada. Pois, de acordo com Labov (1983), uma análise da transmutação linguística não constitui uma mera descrição da gramática, e sim uma descrição linguística que está acima dos livros de gramática.

Assim sendo, a variável é essencial para a maestria sociolinguística, nas quatro atividades: falar, ouvir, ler e escrever. Vale frisar que a habilidade sociolinguística é um fator imprescindível com o objetivo cujo aluno desenvolva sua competência comunicativa. Toda via, é fundamental que o discente tenha noção da heterogeneidade linguística do lusitânico. Nesse sentido, é essencial que haja um trabalho no que se refere à ocorrência das variedades dessa língua.

\section{A CULTURA}

$\mathrm{Na}$ antiguidade, o termo cultura é originada do verbo latino colere, o qual designava o preceito de cultivar, tomar conta, cuidar da natureza. Cultura era a formação das pessoas, a evolução do caráter e do temperamento dos indivíduos. Chauí (2005), afirma ao longo da história, vários sentidos foram atribuídos à palavra cultura. Segundo a filósofa, a datar do século XVIII, cultura passou a significar o resultado da formação do individuo, em suma, cultura é o todo complexo que inclui conhecimentos, crenças, arte, moral, leis, costumes ou qualquer outra capacidade ou hábitos adquiridos pelo homem enquanto membro de uma sociedade.

Pode-se dizer que a cultura é um conjunto de ideias, comportamentos, símbolos e práticas sociais artificiais assimilados de geração em geração mediante o convívio social. Neste contexto, fica claro que cultura é o conjunto de manifestações humanas que contrastam com a natureza ou comportamento natural. A citação de Chauí (2005) demonstra que se passou a dizer que cultura é toda produção humana, e esta depende do indivíduo e do seu contexto social. Quanto à língua é indubitável que se 
trata de uma produção cultural, pois é elaborada por seres humanos no âmbito sociável.

É interessante, aliás, salientar o quanto a língua é um poderoso mecanismo de recognição de um povo, mas há um fato que se sobrepõe, a fala é o gênero mais comum, autêntica e dinâmica. Mesmo assim, não parece haver razão para que a oralidade se diversifique apenas no espaço social, pessoal ou interpessoal; ela modifica-se inclusive no tempo. Conforme explicado acima é sinal a fala é um fator de identificação cultural.

Se, no entanto, a língua é vista como um meio de interação utilizado pelos homens de uma determinada sociedade para se fizer compreender e for compreendido, não pode conceber o ensino de línguas dissociado da cultura. Ao usar a linguagem, as pessoas expressam ideias, opiniões, modos de ver e pensar o mundo que são partilhados com outras pessoas. A língua expressa incorpora e simboliza uma realidade cultural. (TAVARES, 2006, p.61).

Por fim, podemos chegar à conclusão que a forma natural de falar de qualquer ser humano colabora com poderio para reconhecer a si próprio e para ser reconhecido pelo outro. Logo, é indiscutível que na realidade é um fator de identificação cultural, mas no uso, e pelo uso, que dela faz o indivíduo no âmbito em que está inserido e não somente por remeter-se a uma das várias comunidades que a utilizam a mesma língua.

\subsection{COMBATE A INTOLERÂNCIA E A DISCRIMINAÇÃO}

A intolerância consiste no ato, conjunto de atos ou manifestações que expressam o desrespeito, repudio ou desprezo da dignidade, características, convicções e opiniões de seres humanos por serem diferentes ou contrárias. A intolerância não é apenas uma característica da "personalidade" de indivíduos, mas também um elemento presente em sociedade em instituições dentre outros. Na linguística a intolerância existe, mas passa quase despercebida. Conforme mencionado pelos PCN [Parâmetros Curriculares Nacionais] (1998), a discriminação de algumas variedades 
linguísticas, tratadas com prejulgamento e anticientífica, evidencia os verdadeiros conflitos existentes no interior da sociedade.

No entanto, pode-se ratificar que a intransigência estabelece o vínculo entre as numerosas variantes constituintes da língua e os preceitos de uma variedade de língua que não a do grupo em que se encontra incluído. Neste contexto, segundo Barros (2004), fica claro que a língua tem função social e está relacionada com ao menos duas questões que envolvem a discriminação: a primeira determina a língua melhor ou pior que outas; a segunda é homologada com posições sociais inferiores ocupadas por determinados grupos. Não é exagero trazer a baila que a intolerância linguística existe e é tão agressivo quanto qualquer outra e deve ser combatida com vigor.

Conforme explicado acima é interessante, aliás, afirmar que toda língua comporta em si mesmos critérios e elementos distintivos suficientes para engendrar as atitudes de identificação e de exclusão a respeito dos participantes da comunicação real ou suposta, pois todos os fatos linguísticos são suscetíveis de serem conotados socialmente, mas há um fator que se sobrepõe como acabar com rejeição de um sistema de comunicação específico é algo difícil. É preciso sempre que faça a distinção entre preconceito e discriminação. É preciso combater a discriminação, ou seja, quando esse preconceito deixa de ser apenas um comportamento ou uma maneira de julgar dos indivíduos e se metamorfoseia em normas sociais.

Professores, estudantes e usuários em geral da língua devem saber reconhecer o preconceito e a intolerância linguística para, de um lado, atuar crítica e conscientemente diante de ocorrências desses fenômenos e, de outro, para ajudar a evitar sua manifestação. Tal atitude faz parte da formação integral do cidadão, pois é, também, indicativo de respeito pelas diferenças do outro. (LEITE, 2012, p.14).

Assim sendo, a incomplacência linguística forma-se pela oposição a meio-termo da utilização e certa metáfora do dialeto vernáculo que transpassa o senso comum da sociedade. Conseguimos compreender de acordo com o que foi relatado anteriormente que essa tensão constitutiva da intolerância linguística não ocorre apenas no nível da forma do conteúdo, mas também no da expressão. Não é demasia 
dizer que essa temática precisa ser compreendida como um quesito linguístico, público e ideológico, gerado então uma idealização das formas linguísticas que se transforma em parâmetro de julgamento em relação àqueles que não seguem os padrões normativos. Assim, a hierarquização grupal dar homologação a uma categorização linguística onde aqueles que não fazem uso da norma linguística estabelecida socialmente são considerados, quase automaticamente, inferiores, inadequados, ignorantes, etc.

\section{METODOLOGIA}

Em concordância com Rampazzo (2005), pesquisa é um agrupamento de táticas reflexivas que outorga descobrir novos acontecimentos em qualquer área do conhecimento. Pesquisar é realizar um encadeamento de coleta, interpretação baseada em técnicas com a finalidade de sintetizar respostas sobre um determinado material de estudo.

A análise dos dados nas pesquisas experimentais e nos levantamentos é essencialmente quantitativa, o mesmo não ocorre, no entanto, com as diligências definidas como estudos de campo, estudos de caso, pesquisa-ação ou pesquisa participante. Nestas, os procedimentos analíticos são principalmente de natureza qualitativa. (VOZES, 2008, p.95-124)

Conforme citado acima, devido à utilização de uma retificação de uma coleção de obras literárias com base em fichamento de livros, será utilizada a interpelação qualitativa para tratamento dos dados pertinentes a perspectiva que se fará acerca das fontes bibliográficas exploradas. Nesse sentido, devido ao sustentáculo da pesquisa ser um infortúnio, tem-se uma variedade de juízo hipotético-dedutivo baseado em uma hipótese onde possa chegar a uma sustentação de solução viável para o problema. Segundo Prodanov (2013, p. 51), "a pesquisa básica objetiva gerar conhecimentos novos úteis para o avanço da ciência sem aplicação prática prevista. Envolve verdades e interesses universais".

A pesquisa explicativa busca distinguir os motivos que causam um determinado fenômeno, aprofundando a consciência da veracidade explicando o porquê dos 
pensamentos. Explicar os fatos de forma científica. Estudar um cenário problema e através do experimento tentativa e erro, identifica e explica o que contribuiu para o incidente do fenômeno. (CIRIBELLI, 2003).

A pesquisa foi desenvolvida e classificada de forma que fosse possível atingir o objetivo da pesquisa de forma mais eficiente. Para uma melhor análise desta pesquisa, percebeu-se que ela é considerada como pesquisa explicativa por causa da veracidade na utilização de fontes bibliográficas e descritivas para que fosse possível descrever todo o processo.

Como instrumento para contribuição de materiais utilizou-se resumos através de fichamentos. Tendo como base os livros de maior relevância sobre o enunciado, a fim de se obter uma melhor apreciação do conteúdo apresentado no trabalho. Com esse gênero é possível levantar as informações mais importantes a respeito da tese a qual servirá como matriz de informações para a retificação de literatura.

A interpelação do trato da subscrição de elementos da pesquisa será bibliográfica, visto que implica em aspectos e informações necessárias para realização da mesma sejam atingidos através do avanço de escritores aptos através de documentos como livros, trabalhos científicos, sites e revistas especializadas, e assim por diante.

Portanto, a pesquisa foi realizada mediante leitura sistemática e produção de fichamentos, a começar de livros, artigos, e fontes eletrônicas que abordam o tema proposto para opor-se ao problema. Tendo como foco a análise bibliográfica da língua materna e da variante linguística das regiões brasileiras com um checape geral nas variedades populares da língua. Em que mostrará efeitos catastrófico do preconceito linguístico.

\section{CONSIDERAÇÕES FINAIS}

O desenvolvimento do presente estudo não buscou analisar se uma ideologia é precisa ou incorreta, porém respaldá-la, de modo que se possa compreender como 
ela pode influenciar um determinado conceito em relação a outrem, ou inclusive um procedimento óptico a um tema.

Essa pesquisa possibilitou analisar o preconceito linguístico e sua realidade, foi feita uma reflexão acerca das causas e das consequências encontradas ao se tratar desse conteúdo, além disto, como também possibilitou usar diversas indicações bibliográficas e avaliar como essas referências auxiliam tanto no trabalho do professor como na aprendizagem dos discentes.

De um modo geral, a escola teria o dever e obrigação de incluir os discentes e não fazer o contrário como vemos por aí. As instituições escolares devem considerar a realidade de seus alunos buscando alternativas que valorizem as vivencias e a realidade dos educandos, a fim de que eles se sintam valorizados, tanto como indivíduos quanto como falantes da língua.

Presenciamos nos dia-a-dia preconceitos sociais envolvendo $o$ analfabeto e certas variantes do português utilizadas por classes sociais mais desajudadas e indefesas, nas metrópoles e nos campos, tanto financeiramente quanto na educação formal. As análises bibliográficas mostram como a língua além de ser um dos elementos necessários para a constituição de identidades, é também um dos mecanismos presentes nas posturas preconceituosas e comportamentos intolerantes em relação aos não letrados e classes sociais de baixo extrato do passado, do presente e, se não atentarmos para esse fenômeno, do futuro.

Dada à gravidade do tema, torna-se necessário entender que uma língua tem como objetivo fundamental a comunicação e a interação dos indivíduos, e as instituições educacionais do nosso país carecem expor para seus aprendizes que há sim discriminação no meio dos discursos nas mais inúmeras situações, mas que a linguagem deles não é ilegal ou menos qualificada que outra qualquer. Uma vez que estabeleceu à comunicação, realizou-se, pois, a principal missão da língua. Nesse sentido, é preciso ter consciência que este infortúnio é proveniente da identidade do individuo, intimamente relacionada com os fatores sociais e econômicos que permeiam as relações entre os grupos sociais marcadas pela linguagem que 
utilizam. Tristemente, inúmeras escolas têm se caracterizado pela discriminação e com condutas inaceitáveis, contudo, não é admissível que o professor tenha resquícios de preconceitos linguísticos.

\section{REFERÊNCIAS}

BAGNO, Marcos. Preconceito linguístico: O que é, como se faz. São Paulo: Loyola. 49‥ed. 2007.

BECHARA. Evanildo. Moderna gramática portuguesa. Rio de Janeiro: Lucerna. 37ํ.ed. 2001.

Ensino da gramática: opressão?, liberdade?. São Paulo: Ática - $12^{\circ}$. ed. 2006

BELINE, R. A variação linguística. In: Introdução à Linguística. São Paulo: Contexto, 2002.

BORBA, Francisco da Silva. Introdução aos estudos linguísticos. Campinas, SP: Pontes, 12a . ed. 1998.

CHAGAS, P. A mudança linguística. In: Introdução à Linguística. São Paulo: Contexto, 2002.

FIORIN, José Luiz et al. Introdução à Linguística. I. Objetos teóricos. 5. Ed. São Paulo: Editora contexto, 2006.

FIORIN, José Luiz. et al. Introdução a Linguística. São Paulo. Contexto. 6. Ed. 2010

HILL. Archibald A. Aspectos da linguística moderna. São Paulo: Cultrix. 1972

LEITE, Marli Quadros. Preconceito e intolerância na linguagem. Coleção linguagem \& ensino. São Paulo: Editora Contexto, 2012. 
LOPES, Edward. Fundamentos da linguística contemporânea. São Paulo: Cultrix. 1979

MARTELOTTA, M.E. (Org.) et al. Manual de Linguística. São Paulo: Contexto, 2008. NUNES, Paula Ávila. Ferdinand de Saussure e o curso de linguística geral: Que linguística?. Disponível em:

$<$ http://www.letras.ufscar.br/linguasagem/edicao17/art_nunes.php> Acessado em 13 de maio de 2012

SAUSSURE, Ferdinand de. Curso de linguística geral. Tradução de Antônio Chelini, José Paulo Paes e Izidoro Blikstein. 27. ed.São Paulo: Cultrix, 1996.

TAVARES, R. R. Língua, cultura e ensino. Maceió: UFAL.2006.

VIANA, Nildo. Educação, Linguagem e Preconceito linguístico. Plurais. Vol. 01, n. 01.2004

Enviado: Março, 2020.

Aprovado: Agosto, 2020. 